\title{
Electrochemical Behavior of Three CP Titanium Dental Implants in Artificial Saliva
}

\author{
Norma Terumi Kadowaki, Gustavo Aristides Santana Martinez*, Alain Robin \\ Department of Materials Engineering - LOM - EEL-USP \\ Pólo Urbo Industrial, Gleba AI-06, P.O. BOX 116, 12600-970 Lorena - SP, Brazil
}

Received: May 15, 2009; Revised: August 18, 2009

\begin{abstract}
The electrochemical behavior of three titanium dental implants purchased on the Brazilian market was evaluated in artificial saliva using open-circuit potential measurements, electrochemical impedance spectroscopy and potentiodynamic polarization. The three implants are passive in this medium but their corrosion resistance and the stability of their passive oxide films are quite different. Although the three implants were made of commercially pure grade titanium, their corrosion current densities and passive current densities were shown to differ from one to two orders of magnitude.
\end{abstract}

Keywords: dental implants, titanium, corrosion, electrochemical techniques

\section{Introduction}

Titanium has been widely used for dental implants and restorations due to its good osseointegration, excellent corrosion resistance and biocompatibility in biological fluids and high resistance/weight ratio $^{1}$. The influence of contaminants and surface treatments of titanium implants (alumina-blasting, acid etching, anodization, hydroxyapatite coating, for example) on osseous integration has been extensively studied. Many works have been also published on the corrosion behavior of commercially pure titanium in artificial saliva, Ringer, Hanks solutions and others ${ }^{2-6}$. All the authors agree that the titanium corrosion resistance in these media is due to the formation of an adherent and highly protective oxide film on its surface which is mainly formed of $\mathrm{TiO}_{2}{ }^{[7]}$. Nevertheless, this oxide can lose its chemical stability under certain conditions. In fluoride medium for example, titanium can be severely attacked depending on the $\mathrm{pH}$ due to the formation of stable titanium fluoride and oxy-fluoride compounds ${ }^{8}$. In spite of the abundant bibliography on titanium corrosion properties, no study was found about the corrosion resistance of commercial titanium implants. Although titanium implants are considered as highly corrosion resistant materials for applications in body fluids, the determination of their corrosion rate is of great importance. Indeed, some studies indicated that titanium release in the organism, even at low levels, can lead from local discoloration of the tissues to serious inflammatory reactions ${ }^{9-10}$.

The aim of the present work was to study the corrosion behavior of three titanium dental implants purchased on the Brazilian market in artificial saliva, using open-circuit potential measurements, electrochemical impedance spectroscopy and potentiodynamic polarization.

\section{Experimental}

The dental implants (namely A, B and C) investigated in the present work were obtained on the Brazilian market from three different suppliers and are made of grade 2, 3 and 4 CP-titanium, respectively. Their chemical composition according to ASTM F67-95 standard ${ }^{11}$ is reported in Table 1.

Samples were cut from the implants for microstructure analysis, mounted in resin, grounded until 2400 grit, polished using an aqueous suspension of silica powder and finally etched in a modified Kroll solution $\left(3 \mathrm{~mL} \mathrm{HF}+8 \mathrm{~mL} \mathrm{HNO}_{3}+100 \mathrm{~mL} \mathrm{H}_{2} 0\right)$. The three implants present a similar coarse-grained structure but differ in the mean $\mathrm{Ti}$ grain size (Figure 1). The Ti grain sizes of A, B and C implants are in the 50-100, 20-40 and 10-30 $\mu \mathrm{m}$ ranges, respectively.

The remaining materials were machined to nearly $3 \mathrm{~mm}$-diameter cylinders. A copper wire was welded on one side of each cylinder in order to assure the electric contact. Then each cylinder was embedded in resin. The cross-section of the electrode (nearly $7 \mathrm{~mm}^{2}$ exposed area) was mechanically ground with emery-paper up to 600 grit, rinsed with distilled water and dried.

The electrolytic solution used for the electrochemical study was the Fusayama artificial ${ }^{12}$ saliva with the following composition: $0.4 \mathrm{~g} \mathrm{NaCl}+0.4 \mathrm{~g} \mathrm{KCl}+0.795 \mathrm{~g} \mathrm{CaCl}_{2}-2 \mathrm{H}_{2} \mathrm{O}+0.690 \mathrm{~g} \mathrm{NaH}_{2} \mathrm{PO}_{4}-$ $\mathrm{H}_{2} \mathrm{O}+0.005 \mathrm{~g} \mathrm{Na}_{2} \mathrm{~S}-9 \mathrm{H}_{2} \mathrm{O}+1.0 \mathrm{~g}$ urea in $1,000 \mathrm{~mL}$ deionized water. The Fusayama saliva has a natural $\mathrm{pH}$ of 5.5. The saliva was naturally aerated and the experiments were conducted without stirring. The temperature was maintained at $37 \pm 1{ }^{\circ} \mathrm{C}$ using a thermostatic bath. The counter electrode was a square-shaped platinum sheet of $18 \mathrm{~cm}^{2}$ area. All potentials were referred to the saturated calomel electrode $(\mathrm{SCE})$ potential $(=+0.242 \mathrm{~V} / \mathrm{SHE})$.

Open-circuit potential, electrochemical impedance spectroscopy (EIS) and polarization measurements were performed using the Electrochemical Interface SOLARTRON ${ }^{\circledR}$ mod. 1287A and the Frequency Response Analyzer SOLARTRON ${ }^{\circledR}$ mod. 1260 A, controlled by the Ecorr/Zplot SOLARTRON ${ }^{\circledR}$ mod. $125587 \mathrm{~S}$ software.

Prior to polarization experiments, the working electrodes were immersed in the Fusayama saliva for 3 hours, taking the moment of immersion as zero time. Then, impedance measurements at opencircuit potential were made using a sinusoidal signal of $10 \mathrm{mV}$ amplitude and frequencies in the $0.1 \mathrm{~Hz}-100 \mathrm{kHz}$ range. Cathodic and anodic polarization was then carried out potentiodynamically with $0.16 \mathrm{mV} / \mathrm{s}$ sweep rate. After each run, the samples were reground with emery papers to a 600-grit finish in order to remove any product formed on the metal surface which could affect the following tests, rinsed with distilled water and dried. Each experiment was repeated three times. 
Table 1. Chemical composition of the A, B and C CP-Ti dental implants.

\begin{tabular}{cccccccc}
\hline & & Fe max & C max & N max & O max & H max & Ti min \\
\hline A & Grade 2 & 0.10 & 0.03 & 0.015 & 0.15 & 0.005 & 99.7 \\
B & Grade 3 & 0.15 & 0.03 & 0.020 & 0.25 & 0.005 & 99.6 \\
C & Grade 4 & 0.20 & 0.05 & 0.040 & 0.30 & 0.010 & 99.4 \\
\hline
\end{tabular}

wt. $(\%)$

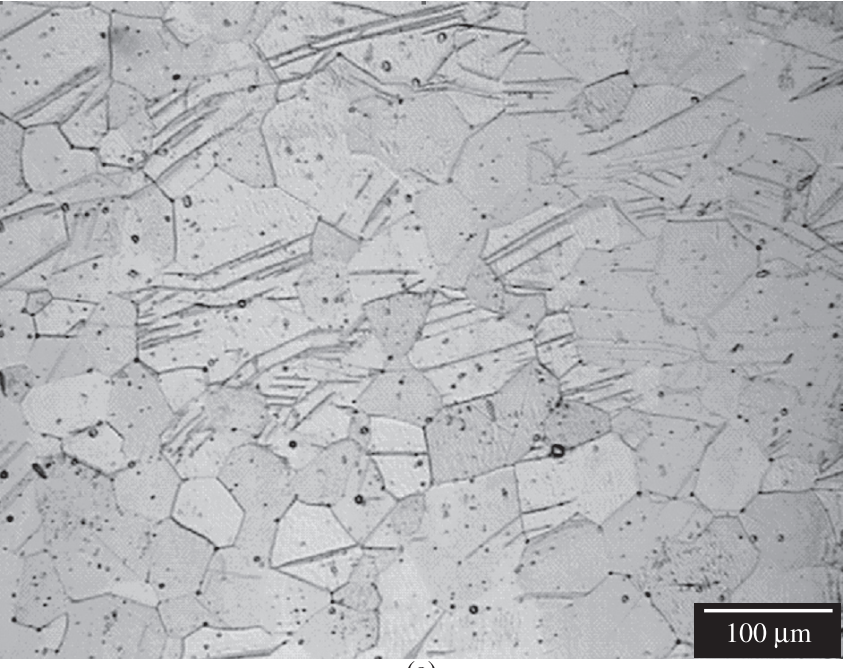

(a)

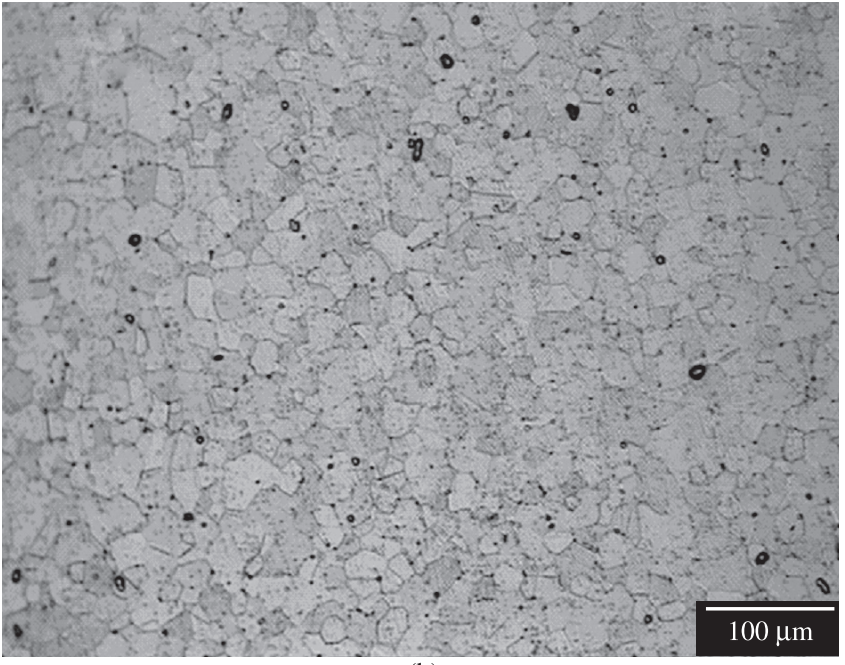

(b)

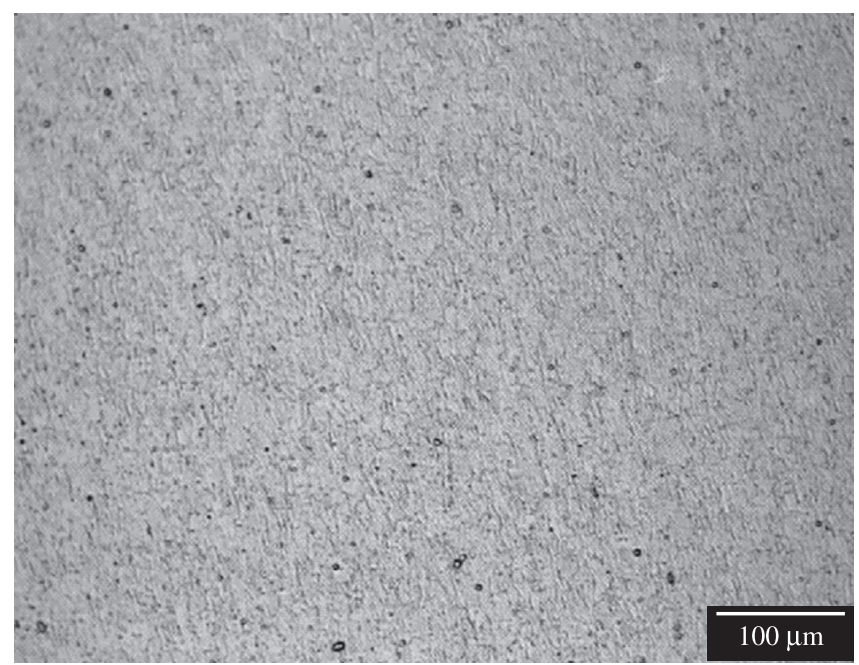

(c)

Figure 1. Microstructures of (a) A, (b) B and (c) C implants.

\section{Results and Discussion}

Figure 2 presents the variation of the open-circuit potential (OCP) of the three Ti implants as a function of exposure time in artificial saliva. All OCPs shift in the noble direction with time which depicts the growth of a passive oxide film on the three implants in this medium. The potential of both A and B implants presents some oscillations, which can be related to some instability of their oxide films. These oscillations are not observed for $\mathrm{C}$ implant.

The open-circuit potentials tend to stabilize with time. Their values after $3 \mathrm{~h}$ exposure, $-0.235,-0.046$ and $+0.075 \mathrm{~V} / \mathrm{SCE}$ for A, $\mathrm{B}$ and $\mathrm{C}$ implants, respectively (or 0.007, 0.196 and $0.317 \mathrm{~V} / \mathrm{SHE}$ ), show that $\mathrm{C}$ implant presents the noblest character, following by $\mathrm{B}$ implant and finally A implant. Nevertheless, all these potentials are found in the stability region of $\mathrm{TiO}_{2}$ oxide in the $\mathrm{Ti}-\mathrm{H}_{2} \mathrm{O}$ Pourbaix diagram for solutions of $\mathrm{pH} 5.5^{[13]}$. A comparison of the implants corrosion potentials in artificial saliva with published data is a difficult task as the OCP of CP-Ti is highly dependent on heat- and mechanical treatments, surface preparation of the samples and exposure time. For example Schiff ${ }^{14}$ and Al-Mayouf ${ }^{15}$ reported OCPs of $+0.025 \mathrm{~V} / \mathrm{SCE}$ and $-0.331 \mathrm{~V} / \mathrm{SCE}$ for CP-Ti in Fusayama artificial saliva, respectively.

Figure 3 shows the polarization curves of the three Ti implants in artificial saliva. The anodic polarization curves have the same shape and are typical of passive behavior. Nevertheless, great differences in the values of anodic current density are evident and this suggests that the passive films formed on the three implants do not have the same stability and that these implants present difference in corrosion resistance. 
The corrosion current density obtained by Tafel extrapolation method and the passive current density measured at 1 V/SCE are reported in Table 2. The results show that the increasing order of corrosion resistance of the Ti implants is: $\mathrm{A}<\mathrm{B}<\mathrm{C}$.

There is difference of two orders of magnitude between corrosion current densities of A and C implants. Schiff ${ }^{14}$ and Al-Mayouf ${ }^{15}$ also reported very different corrosion current density for CP-Ti in Fusayama artificial saliva, $10^{-6}$ and $3.10^{-8} \mathrm{~A} \mathrm{~cm}^{-2}$, respectively.

Considering the corrosion current densities reported in Table 2 and using the Faraday's law for a four-electron transfer, the calculated corrosion rates of A, B and C implants are 43.0, 5.0 and $0.5 \mu \mathrm{m} /$ year, respectively. These values depict the excellent corrosion resistance of the three implants, since it is usually admitted that a metal or alloy

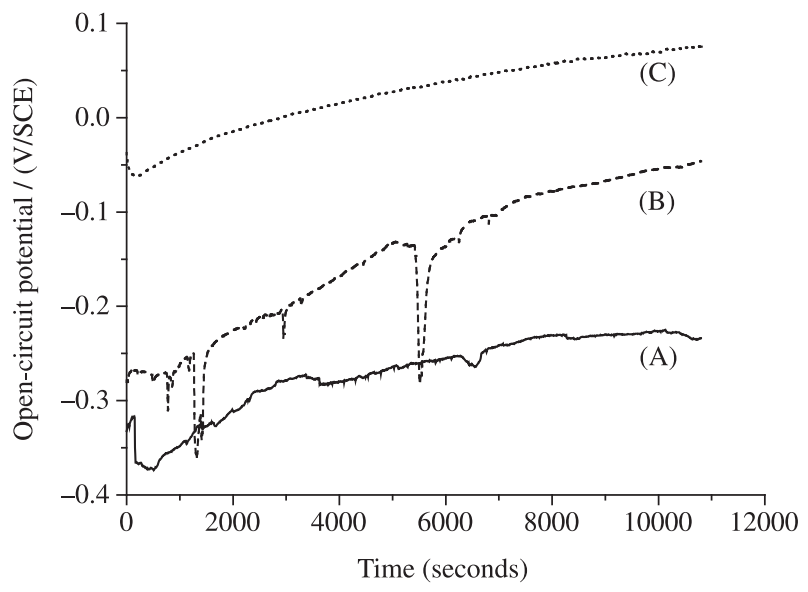

Figure 2. Variation of open-circuit potential for the three Ti implants in artificial saliva.

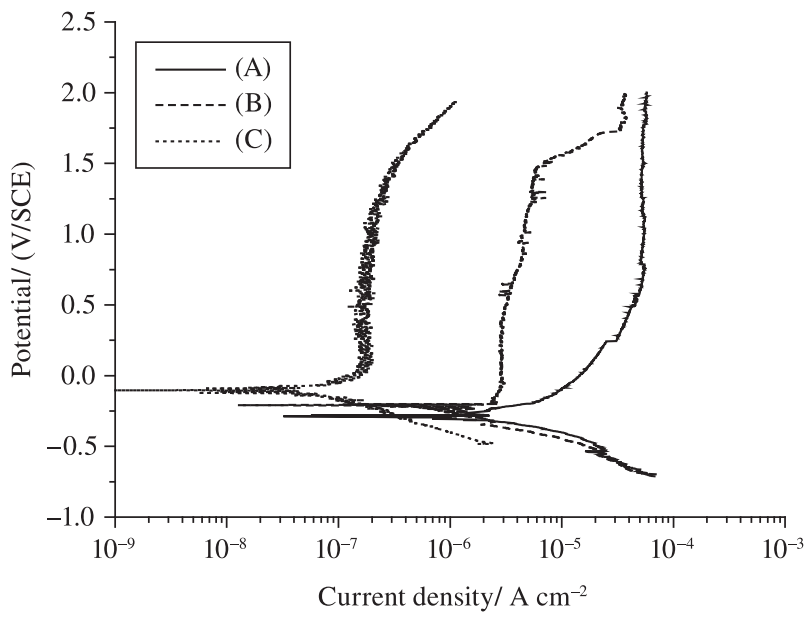

Figure 3. Polarization curves of the three Ti implants in artificial saliva.

Table 2. Corrosion potential, corrosion current density and passive current density (measured at $1 \mathrm{~V} / \mathrm{SCE}$ ) of the three different Ti implants in artificial saliva.

\begin{tabular}{|c|c|c|c|}
\hline Ti implant & A & $\mathrm{B}$ & $\mathrm{C}$ \\
\hline Corrosion potential/ V/ SCE & -0.235 & -0.046 & +0.075 \\
\hline Corrosion current density/ $\mathrm{A} \mathrm{cm}^{-2}$ & $5 \times 10^{-6}$ & $6 \times 10^{-7}$ & $6 \times 10^{-8}$ \\
\hline Passive current density/ $\mathrm{A} \mathrm{cm}^{-2}$ & $5.3 \times 10^{-5}$ & $4.7 \times 10^{-6}$ & $2 \times 10^{-7}$ \\
\hline
\end{tabular}

presents an excellent corrosion resistance when its corrosion rate is in the $25-100 \mu \mathrm{m} /$ year range ${ }^{16}$. Nevertheless, metallic implants generally do not fail due to corrosion damage but due to tissue irritation or infection caused by the corrosion products. Qualitative estimates suggest that implants must corrode at rates of $0.25 \mu \mathrm{m} /$ year or less to avoid the possibility of tissue reaction ${ }^{16}$. Only $\mathrm{C}$ implant corrosion rate is close to this limiting value.

EIS experiments were carried out at OCP in artificial saliva. The Bode diagrams presented in Figures $4 \mathrm{a}$ and $\mathrm{b}$ show that the metal/ solution interface for the three $\mathrm{Ti}$ implants has a predominantly capacitive behavior, which is characteristic of passive materials. Nevertheless the capacitive behavior is limited to a narrower frequency range for A and $\mathrm{B}$ implants, $10^{1}-10^{2}$ and $10^{-1}-10^{2} \mathrm{~Hz}$, respectively. The $\mathrm{C}$ Ti implant presents a capacitive behavior in a larger frequency range, $10^{-1}-10^{3} \mathrm{~Hz}$. This is related to the higher stability of the passive film formed on $\mathrm{C}$ implant, which has already been observed from its polarization curve (Figure 3 ) that shows the lowest values of the anodic current density. The impedance values measured at low frequencies (Figure 4a) indicate that the increasing order of corrosion resistance of the Ti implants in artificial saliva is: $\mathrm{A}<\mathrm{B}<\mathrm{C}$.

The difference in chemical composition of the three Ti implants (grade 2, 3 and 4 for A, B and C, respectively) cannot explain the superior resistance of $\mathrm{C}$ implant and the lowest resistance of $\mathrm{A}$ im-

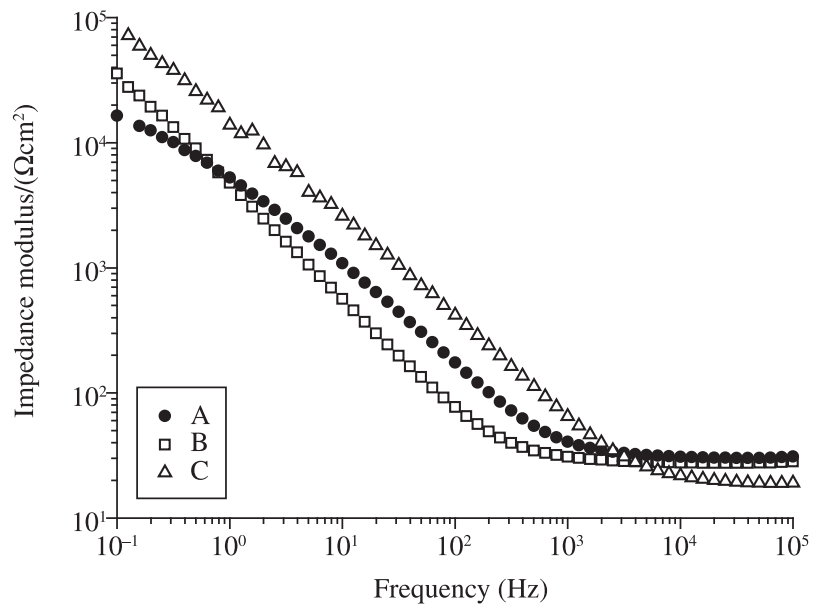

(a)

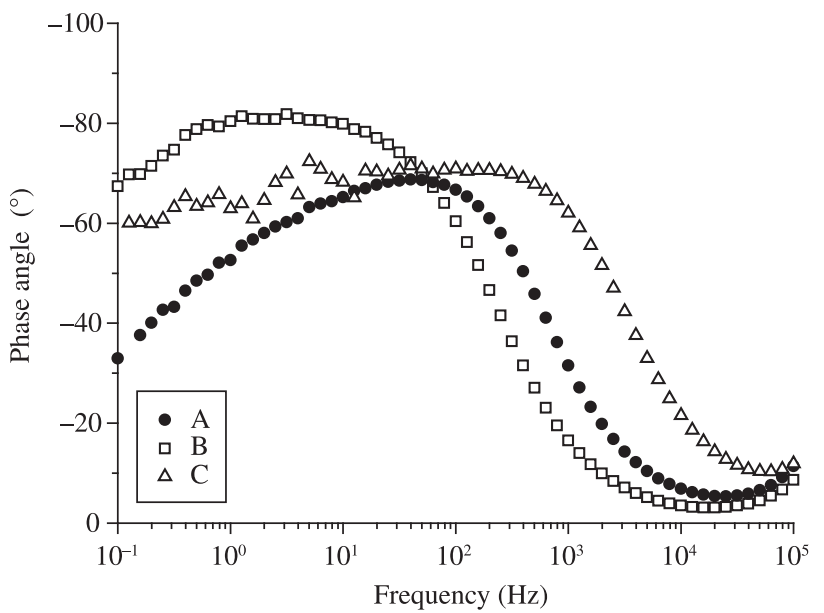

(b)

Figure 4. Bode diagrams of the three Ti implants obtained at OCP in artificial saliva: (a) impedance modulus vs frequency and (b) phase angle vs frequency. 
plant. Indeed, the general corrosion resistance of commercially pure Ti grades is quite similar and our results showed differences of one to two orders of magnitude for corrosion current densities of the implants. ASTM grade 2 is only more resistant than ASTM grades 3 and 4 to stress corrosion cracking in chloride media. The difference in Ti grain size (Figure 1) cannot also explain the difference in corrosion resistance of the three Ti implants. Indeed, for most metals and alloys a decrease in corrosion resistance is usually observed when the grain size diminishes ${ }^{17-18}$. From the grain size standpoint, the increasing order of corrosion resistance should be $\mathrm{C}<\mathrm{B}<\mathrm{A}$. An improvement in corrosion resistance of CP-Ti grade 2 in simulated body fluid was already observed but for ultra fine grained microstructure (sub-micron grain size $)^{19}$. Then, other reasons such as heat- and mechanical treatments during manufacture of the implants may be raised to explain the significant difference in the corrosion resistance of the three implants.

\section{Conclusions}

The corrosion behavior of three commercially pure Ti dental implants purchased on the Brazilian market from three different suppliers was evaluated in artificial saliva using electrochemical techniques.

The three implants present a passive behavior in this medium and high corrosion resistance. Nevertheless their corrosion resistance and the stability of their passive oxide films are quite different.

The corrosion current densities of the three implants were shown to differ from one to two orders of magnitude.

Nor the chemical composition neither the Ti grain size of the implants could explain this difference in corrosion resistance.

\section{References}

1. Jones FH. Teeth and bones: applications of surface science to dental materials and related biomaterials. Surface Science Reports. 2001; 42(3-5):75-205.

2. Pan J, Thierry D and Leygraf C. Electrochemical impedance spectroscopy study of the passive oxide film on titanium for implant application. Electrochimica Acta. 1996; 41(7-8):1143-1153.

3. González JEG and Mirza-Rosca JC. Study of the corrosion behavior of titanium and some of its alloys for biomedical and dental implant applications. Journal of Electroanalytical Chemistry. 1999; 471(2):109-115.

4. Koike M and Fujii H. In vitro assessment of corrosive properties of titanium as a biomaterial. Journal of Oral Rehabilitation. 2001; 28(6):540-548.
5. Ibris N and Mirza-Rosca JC. EIS study of Ti and its alloys in biological media. Journal of Electroanalytical Chemistry. 2002; 526(1-2):53-62.

6. Shukla AK, Balasubramaniam R and Bhargava S. Properties of passive film formed on CP titanium, Ti-6Al-4V and Ti-13.4Al-29Nb alloys in simulated human body conditions. Intermetallics. 2005; 13(6):631-637.

7. American Society for Metals Handbook. Corrosion. Materials Park: ASM International; 1993.

8. Boere G. Influence of fluoride on titanium in an acidic environment measured by polarization resistance technique. Journal of Applied Biomaterials. 1995; 6(4):283-288.

9. Black J, Sherk H, Bonini J, Rostoker WR and Galante JO. Metallosis associated with a stable titanium-alloy femoral component in total hipreplacement. A case report. Journal of Bone and Joint Surgery. 1990; 72(1):126-130.

10. Amstutz HC, Campbell P, Kossovsky N and Clarke IC. Mechanism and clinical significance of wear debris-induced osteolysis. Clinical Orthopaedics e Related Research. 1992; 276:7-18.

11. American Society for Testing and Materials. Medical Devices and Services. Standard Specification for Unalloyed Titanium for Sirurgical Implant Applications. West Conshohocken, PA; 1997. p. 1-3. [Annual Book, v.13].

12. Baboian R. Corrosion Tests and Standards: Application and Interpretation. USA: ASTM; 1995

13. Pourbaix M. Atlas of Electrochemical Equilibria in Aqueous Solutions. New York: Pergamon Press; 1966.

14. Schiff N, Grosgogeat B, Lissac M and Dalard F. Influence of fluoride content and $\mathrm{pH}$ on the corrosion resistance of titanium and its alloys. Biomaterials. 2002; 23(9):1995-2002.

15. Al-Mayouf AM, Al-Swayih AA, Al-Mobarak NA and Al-Jabab AS. Corrosion behavior of a new titanium alloy for dental implant applications in fluoride media. Materials Chemistry and Physics. 2004; 86(2-3):320-329.

16. Fontana MG. Corrosion Engineering. New York: McGraw-Hill Book Company; 1986.

17. Di Schino A and Kenny JM. Effects of the grain size on the corrosion behavior of refined AISI 304 austenitic stainless steels . Journal of Materials Science Letters. 2002; 21(20):1631-1634.

18. Osório WR, Siqueira CA, Freire CMA and Garcia A. Efeito das diferentes morfologias estruturais e tamanho de grão na resistência à corrosão em amostras de alumínio e zinco puros. In: 60 Conferência sobre Tecnologia de Equipamentos; Salvador-Brazil; 2002.

19. Balakrishnan A, Lee BC, Kim TN and Panigrahi BB. Corrosion behavior of ultra fine grained titanium in simulated body fluid for implant application. Trends in Biomaterials and Artificial Organs. 2008; 22(1):54-60. 